\title{
Advances in Scalable Implantable Systems for Neurostimulation Using Networked ASICs
}

\author{
Xiao Liu, Member, IEEE, Zhulin Zong, Member, IEEE, Dai Jiang, Member, IEEE, Bachir Bougaila, \\ Nick Donaldson, and Andreas Demosthenous, Senior Member, IEEE
}

\begin{abstract}
Neurostimulation is a known method for restoring lost functions to neurologically impaired patients. This paper describes recent advances in scalable implantable stimulation systems using networked application specific integrated circuits (ASICs). It discusses how they can meet the ever-growing demand for high-density neural interfacing and long-term reliability. A detailed design example of an implantable (inductively linked) scalable stimulation system for restoring lower limb functions in paraplegics after spinal cord injury is presented. It comprises a central hub implanted at the costal margin and multiple Active Books which provide the interface for stimulating nerve roots in the cauda equina. A 16-channel stimulation system using four Active Books is demonstrated. Each Active Book has an embedded ASIC, which is responsible for initiating stimulus current to the electrodes. It also ensures device safety by monitoring temperature, humidity, and peak electrode voltage during stimulation. The implant hub was implemented using a microcontroller-based circuit. The ASIC in the Active Book was fabricated using XFAB's 0.6- $\mu \mathrm{m}$ high-voltage CMOS process. The stimulation system does not require an accurate reference clock in the implant. Measured results are provided.
\end{abstract}

Index Terms-Active Books, humidity measurement, implantable stimulator, low power, networked ASICs, neurostimulation, reliability, scalable stimulation system, temperature measurement.

\section{INTRODUCTION}

$\mathrm{D}$ AMAGE or degradation to the central and peripheral nervous systems due to injury or disease results in loss of neural function in various parts of the body. Neuroprostheses may assist in partial restoration of function and mobility using neurostimulation. It involves passing pulses of electrical current into muscle tissue or nerve branches, which cause activation or excitation of targeted muscles or neural tissues.

Manuscript received June 23, 2015, revised December 23, 2015, accepted January 15, 2016. This work was supported by the U.K. Engineering and Physical Sciences Research Council (EPSRC) under Grant EP/F009593/1.

X. Liu, D. Jiang, B. Bougalia and A. Demosthenous are with the Department of Electronic and Electrical Engineering, University College London, London WC1E 7JE, UK. (e-mail: xiao@ucl.ac.uk; d.jiang@ucl.ac.uk; bachir.bougaila@ucl.ac.uk; a.demosthenous@ucl.ac.uk).

Z. Zong was with the Department of Electronic and Electrical Engineering, UCL, London WC1E 7JE, U.K. He is now with the University of Electronic Science and Technology of China, 611731, Chengdu, China (zongzhulin@uestc.edu.cn).

N. Donaldson is with the Department of Medical Physics and Bioengineering, University College London, London WC1E 6BT, UK. (email: n.donaldson@ucl.ac.uk).
The first neurostimulation systems were reported in the early sixties [1]. Since then they have developed into fully implantable devices employing wireless telemetry for the transmission of power and control signals [2], [3]. The most commercially successful neuroprosthesis to date, the cochlear implant, processes sound at different frequencies into amplitude modulated electrical pulses which stimulate multiple sites along the cochlea. The method has successfully restored hearing for thousands of patients [4]. Using a similar principle, limited sight can be restored by translating visual signals into multi-site electrical stimulation on the retina [5], [6]. Similarly, balance can be restored by converting head motion into frequency modulated current pulses to the vestibular organs [7], [8], [9], and locomotor functions, such as standing and walking, can be restored by coordinated stimulation on the spinal cord [10], [11], [12].

Stimulators with extremely high channel count have been reported, such as 232 channels for visual prosthesis [13], 64 channels for deep brain stimulation [14], 22 channels for cochlear stimulation [15] and 16 channels for spinal cord stimulation [16]. It is expected that an even higher channel count will be needed to achieve finer neuron-device interaction. There are two different approaches to address this: i) integrate as many stimulation channels as possible on a single ASIC, and ii) use a scalable system with networked ASICs where each ASIC addresses a fraction of the stimulating channels. While there is no immediate limitation in silicon technology on how many channels can be included on an ASIC, the number of stimulating channels per ASIC is usually limited by practical issues, such as the reliability of multiple interconnections to and from the stimulator ASIC [17]. For some neural applications, groups of stimulation sites may not be physically close. In such cases, cable management and implantation procedure is easier if stimulation sites in close proximity are grouped together and a stimulator ASIC is assigned to manage only the nearby sites.

The rest of the paper is organized as follows. Section II discusses current challenges as stimulator implants become smaller and feature many more channels. It provides a literature review on recent advances in scalable implantable stimulation systems for neurostimulation using networked ASICs. A detailed design example is presented in Sections III-V. The system architecture is described in Section III. Section IV discusses the circuit design of the key functional blocks, including the telemetry and ASIC. Measured results 


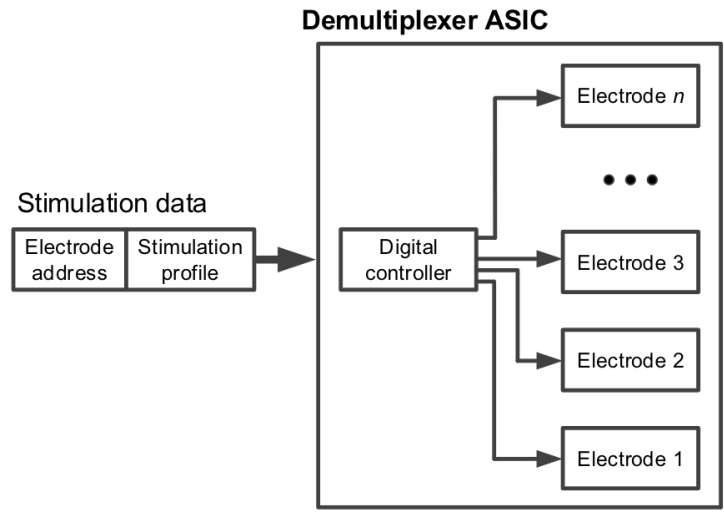

(a)

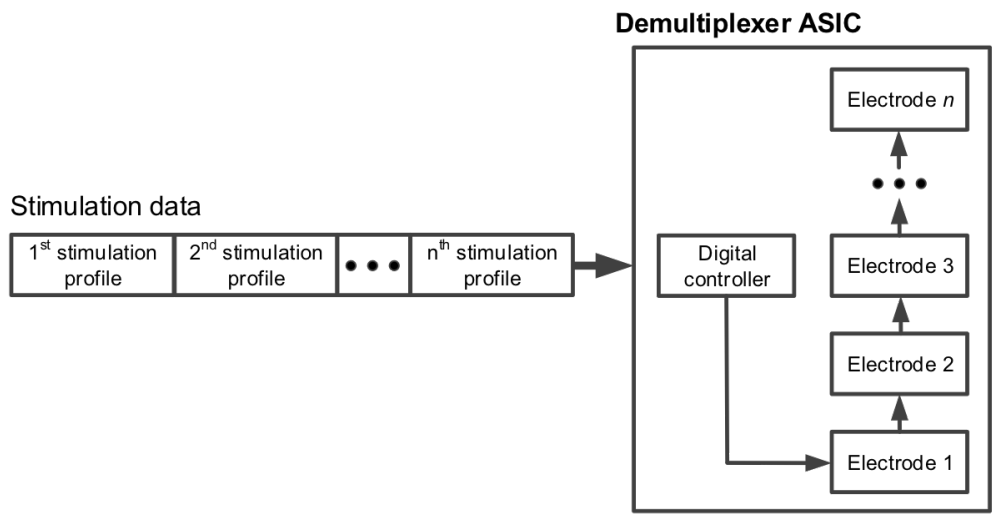

(b)

Fig. 1. Different methods of addressing electrodes: (a) parallel configuration; (b) series shift configuration.

are presented in Section V, followed by concluding remarks in Section VI.

\section{Scalable Stimulation Systems Using Networked ASICS: CHALLENGES AND STATE-OF-THE-ART}

\section{A. Leads Count}

As the number of stimulation channels increases the number of interconnect wires between a stimulator and an electrode array increases. The width of the interconnect cable containing the wires then becomes impractical to be safely implanted. For example, it is expected that a spinal cord stimulator on nerve rootlets in the spine would require 96 channels for more selective and direct muscle activation: 6 (i.e., L2 to S2 segments of the spine) $\times 8$ (rootlets per nerve root) $\times 2$ (sides) [18]. This would require 192 and 288 leads for dipole and tripole stimulators, respectively. High cable count is not only a significant challenge for surgeons to implant the cables safely [19], but also causes a significant percentage of implant failures [20], [21].

To overcome this problem a demultiplexer ASIC can be added to the electrode array itself [22]. Such a configuration is known as "active electrode" because it moves the demultiplexer from the stimulator (start of the interconnect cable) to the electrode array (end of the interconnect cable). There are two different forms of demultiplexing, direct demultiplexing and regenerative demultiplexing, depending on how the demultiplexer ASIC handles the input. Giagka et al. [11] presented a demultiplexer ASIC for driving epidural electrodes. One of the inputs to the ASIC is the stimulus current; other inputs include power and data to define which stimulation site the stimulus current accesses. The demultiplexing takes place directly from the input current. Although easy to implement, it is not possible in direct demultiplexing to provide different currents for different stimulation sites in the same demultiplexer ASIC. An alternative approach is to send only the data and power to the demultiplexer which works out the specification needed for stimulation from the input data, generates the necessary stimulus, and steers it to the chosen channel. It is at the demultiplexer ASIC that the stimulus current is regenerated.
Since the data and power can be modulated together, the theoretical minimum number of input leads for this approach is two. In practice it is common to use dedicated power and data wires (which may include a separate clock wire, a demultiplexer specific enable wire and a wire for stimulation commands). The total number of input wires for a demultiplexer then varies between two and nine [9], [10], [11], [23], [24], [25], [26], [27], [28] which can fit into a helical cable and be implanted safely.

Demultiplexing compromises the flexibility of simultaneous stimulation. To the authors' best knowledge there is no reported neural stimulation application that requires all stimulation sites to be activated at the same time. Hence, most stimulators should be able to provide a certain level of demultiplexing.

\section{B. Addressing Stimulating Electrodes}

In a multi-channel stimulator, the stimulus currents flow through the selected electrodes, which are typically individually addressed. Two different configurations exist to address electrodes, parallel and serial shift, as shown in Fig. 1. In the parallel configuration, each electrode has an address. By specifying the target electrode's address, the controller can arbitrarily stimulate any site and thus any stimulation sequence is possible. The disadvantage of this method is the increase in the size of the data packet due to the extra overhead needed for address bits. It requires a higher data rate at the telemetry. If an implant system contains multiple demultiplexers, each ASIC needs to differentiate itself from others by a unique ID. This not only increases data rate, but also complicates the electronics design as each ASIC needs to be programmed differently to set up the unique address ID.

The serial shift configuration has the stimulus data for all electrodes arranged in a predetermined fashion. Because the electrodes are sequentially addressed, each electrode address need not be in the data packet and the data rate is lower than in the parallel configuration. The implant system can drive more electrodes by appending the extra channels to existing channels. The disadvantage of the serial shift configuration is that flexible arbitrary stimulation is limited because the sequence in which different electrodes are addressed is fixed. 
TABLE I

COMPARISON OF SCALABLE IMPLANTABLE NEUROSTIMULATION SYSTEMS USING NETWORKED ASICS

\begin{tabular}{|c|c|c|c|c|c|c|c|}
\hline Reference & Application & $\begin{array}{c}\text { Network } \\
\text { Topology }\end{array}$ & $\begin{array}{c}\text { Stimulation } \\
\text { DeMUX } \\
\text { Type }\end{array}$ & $\begin{array}{c}\text { ASICs per } \\
\text { System }\end{array}$ & $\begin{array}{c}\text { Channels per } \\
\text { System }\end{array}$ & $\begin{array}{c}\text { Inputs to } \\
\text { Each ASIC }\end{array}$ & $\begin{array}{c}\text { Methods for Addressing ASICs } \\
\text { and Channels }\end{array}$ \\
\hline$[23],[24]$ & $\begin{array}{c}\text { Cortical } \\
\text { stimulation }\end{array}$ & Daisy chain & Regenerative & 32 & $\begin{array}{c}2048 \\
(64 \text { per ASIC) }\end{array}$ & 2 & $\begin{array}{c}\text { ASICs cannot be individually } \\
\text { addressed. By channel ID }\end{array}$ \\
\hline$[11]$ & $\begin{array}{c}\text { Spinal cord } \\
\text { stimulation }\end{array}$ & Daisy chain & Direct & 3 & $\begin{array}{c}12 \\
\text { (4 per ASIC) }\end{array}$ & 3 & By ASIC ID and channel ID \\
\hline$[25]$ & $\begin{array}{c}\text { Retinal } \\
\text { stimulation }\end{array}$ & Daisy chain & Regenerative & 9 & 9 & 4 & $\begin{array}{c}\text { By ASIC ID and dedicated } \\
\text { channel inputs }\end{array}$ \\
\hline$[9]$ & $\begin{array}{c}\text { Vestibular } \\
\text { stimulation }\end{array}$ & Star-shape & Regenerative & 3 & $\begin{array}{c}18 \\
(6 \text { per ASIC) }\end{array}$ & 5 & $\begin{array}{c}\text { By dedicated ASIC inputs and } \\
\text { channel ID }\end{array}$ \\
\hline $\begin{array}{c}{[10] \text { and }} \\
\text { This work }\end{array}$ & $\begin{array}{c}\text { Spinal cord } \\
\text { stimulation }\end{array}$ & Star-shape & Regenerative & 4 & $\begin{array}{c}64 \\
(32 \text { per ASIC) })\end{array}$ & 6 & $\begin{array}{c}\text { By dedicated ASIC inputs and } \\
\text { sequential channel addressing }\end{array}$ \\
\hline$[28]$ & $\begin{array}{c}\text { Cortical } \\
\text { recording }\end{array}$ & $\begin{array}{c}\text { Daisy chain } \\
\text { By ASIC ID and channel ID }\end{array}$ \\
\hline$[26]$ & $\begin{array}{c}\text { Spinal cord } \\
\text { stimulation }\end{array}$ & $\begin{array}{c}\text { Star-shape for } \\
\text { addressing. } \\
\text { Daisy chain } \\
\text { for stimulus } \\
\text { current }\end{array}$ & Direct & $9+1$ & 27 & 8 & $\begin{array}{c}\text { By dedicated multiplexer inputs } \\
\text { and channel ID }\end{array}$ \\
\hline$[27]$ & $\begin{array}{c}\text { Functional } \\
\text { electrical } \\
\text { stimulation }\end{array}$ & $\begin{array}{c}\text { Daisy chain } \\
\text { (3-6 per ASIC) }\end{array}$ & Regenerative & 16 & $\begin{array}{c}512 \\
(32 \text { per ASIC) }\end{array}$ & 9 & $\begin{array}{c}\text { By sequential ASIC addressing } \\
\text { and channel ID }\end{array}$ \\
\hline
\end{tabular}

${ }^{\xi}$ In the network topology, the daisy chain is a wiring scheme in which multiple ASICs are connected together in sequence or in a ring. All ASICs share the same input in a daisy chain. In a star-shape configuration, the input to individual ASICs from a central device has some wires common to all ASICs and some ASICspecific wires.

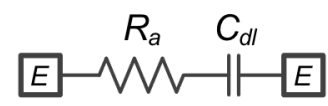

Fig. 2. Simple model of electrode impedance.

In the design example stimulation application in this paper (restoration of motor functions of lower limbs) the stimulation rate is less than $20 \mathrm{~Hz}$ and the longest stimulation phase for a stimulation site is only $1 \mathrm{~ms}$. The serial shift configuration should, therefore, be sufficient and the extra time available between stimulations can be used for completing nonstimulation tasks, such as programming the stimulator ASICs.

Table I summarizes the performance of recent scalable stimulation systems, comparing their system architecture, demultiplexing type, number of channels, number of input connections required, and addressing methods.

\section{Low Power Operation}

In an implantable stimulator power is supplied by an implanted battery or a wireless link. In both cases it is important that the power consumption of the stimulator is kept low (it also reduces the possible heating of the implanted device). The power consumption of an active electrode is

$$
P_{\mathrm{AE}}=V_{\text {supply }}\left(I_{\text {stim }}+I_{\text {other }}\right)
$$

where $V_{\text {supply }}$ is the supply voltage to the stimulator ASIC, $I_{\text {stim }}$ is the stimulus current amplitude and $I_{\text {other }}$ is any other current taken from $V_{\text {supply. }} I_{\text {stim }}$ is mainly dictated by the physiological response of the neural tissue. $I_{\text {other }}$ includes the current necessary for bias circuits, monitoring circuits and signal processing circuits. It tends to be very small compared with

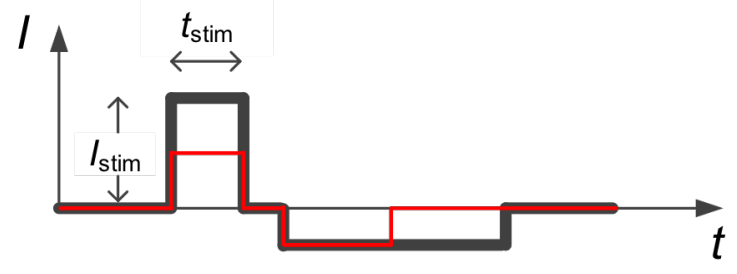

(a)

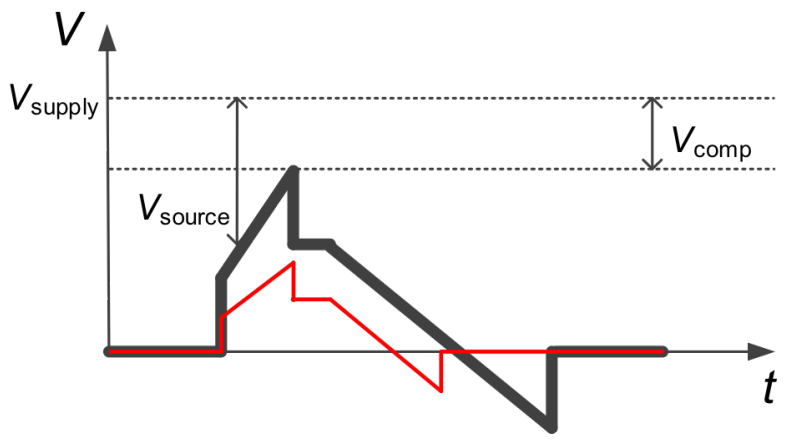

(b)

Fig. 3. Electrical neural stimulation waveforms: (a) a typical biphasic stimulus current; (b) a typical inter-electrode voltage. The black curve indicates the stimulus current and electrode voltage when the stimulus current is high while the red curve is when the stimulus current is low.

$I_{\text {stim }}$ and optimizing $I_{\text {other }}$ has only a small impact on $P_{\mathrm{AE}}$. It is more effective to save power by minimizing $V_{\text {supply. }}$.

Fig. 2 shows the lumped circuit model of the electrodetissue impedance. The supply voltage for a stimulator ASIC is

$$
V_{\text {supply }}=I_{\text {stim }} R_{a}+\frac{I_{\text {stim }} t_{\text {stim }}}{C_{d l}}+V_{\text {source }}
$$

where $t_{\text {stim }}$ is the duration of the stimulus current, $V_{\text {source }}$ is the 
TABLE II

COMPARISON OF STIMULATOR ASICS FEATURING DYNAMIC VOLTAGE SUPPLY

\begin{tabular}{|c|c|c|c|l|l|}
\hline Reference & $\begin{array}{c}\text { Stimulus } \\
\text { Current }\end{array}$ & $\begin{array}{c}\text { High Voltage } \\
\text { Generation }\end{array}$ & $\begin{array}{c}\text { Number of High } \\
\text { Voltage Levels }\end{array}$ & \multicolumn{1}{|c|}{ Control Method } & \multicolumn{1}{|c|}{ Frequency of Adjustment } \\
\hline$[5]$ & $4-992 \mu \mathrm{A}$ & $\begin{array}{c}\text { Shunt } \\
\text { regulator }\end{array}$ & $\begin{array}{c}\text { Limited (not } \\
\text { specified) }\end{array}$ & $\begin{array}{l}\text { By monitoring the gate voltage of } \\
\text { the cascode transistor in the current } \\
\text { generator circuit }\end{array}$ & Adjusted once in a stimulation cycle \\
\hline$[30]$ & $2-504 \mu \mathrm{A}$ & $\begin{array}{c}\text { Switched- } \\
\text { capacitor dc- } \\
\text { dc converter }\end{array}$ & 4 & $\begin{array}{l}\text { By monitoring the gate voltage of } \\
\text { the cascode transistor in the current } \\
\text { generator circuit }\end{array}$ & $\begin{array}{l}\text { Adjusted continuously during the } \\
\text { stimulation }\end{array}$ \\
\hline$[31]$ & Constant $40 \mu \mathrm{A}$ & $\begin{array}{c}\text { Charge pump } \\
\text { Continuous }\end{array}$ & $\begin{array}{l}\text { By monitoring the exact stimulus } \\
\text { current }\end{array}$ & $\begin{array}{l}\text { Adjusted continuously during the } \\
\text { stimulation }\end{array}$ \\
\hline$[33]$ & $20-1000 \mu \mathrm{A}$ & $\begin{array}{c}\text { Zero-voltage } \\
\text { switching }\end{array}$ & Continuous & $\begin{array}{l}\text { By monitoring the voltage } \\
\text { compliance of the current generator }\end{array}$ & $\begin{array}{l}\text { Adjusted continuously during the } \\
\text { stimulation }\end{array}$ \\
\hline$[32]$ & $0-450 \mu \mathrm{A}$ & $\begin{array}{c}\text { Inductive dc- } \\
\text { dc converter }\end{array}$ & Continuous & $\begin{array}{l}\text { By monitoring the electrode voltage } \\
\text { and the exact stimulus current }\end{array}$ & $\begin{array}{l}\text { Adjusted continuously during the } \\
\text { stimulation }\end{array}$ \\
\hline$[34]$ & $80-2480 \mu \mathrm{A}$ & $\begin{array}{c}\text { Adaptive } \\
\text { rectifier }\end{array}$ & 8 & $\begin{array}{l}\text { By monitoring the maximum } \\
\text { electrode voltage }\end{array}$ & Adjusted once in a stimulation cycle \\
\hline This work & $1-8 \mathrm{~mA}$ & $\begin{array}{c}\text { Inductive dc- } \\
\text { dc converter }\end{array}$ & 8 & $\begin{array}{l}\text { By monitoring the maximum } \\
\text { electrode voltage }\end{array}$ & $\begin{array}{l}\text { Adjusted once in a stimulation cycle } \\
\text { (on demand) }\end{array}$ \\
\hline
\end{tabular}

voltage drop across the current generator, $R_{a}$ and $C_{d l}$ are the access resistance and double-layer capacitance of the electrode impedance respectively. The minimum voltage for $V_{\text {source }}$ is known as the compliance voltage, $V_{\text {comp }}$, which maintains the high output resistance of the current generator. During the early part of the stimulation (i.e., $t_{\text {stim }}$ ), $C_{d l}$ begins charging. The electrode voltage is small, resulting in unnecessarily high power wastage at the current generator. As the stimulation progresses, the electrode voltage increases and more power is absorbed in the electrode. Therefore, for a constant supply voltage, the power efficiency is lower at the start of the stimulation and higher towards the end of stimulation. To achieve high power efficiency, for current-mode stimulation, it is desirable to regulate $V_{\text {source }}$ so it remains at $V_{\text {comp }}$ during the entire stimulation phase (i.e., the supply voltage adapts to the electrode voltage). A more radical approach is to remove $V_{\text {source }}$ completely, changing the current-mode stimulator to voltage-mode or charge-mode [29]. While instantaneous adjustment of the supply voltage during the stimulation is possible it usually requires a complex monitoring circuit (for checking the bias voltage in a current generator circuit [5], [30], the instantaneous stimulus current [31], [32], the voltage compliance of a current generator circuit [33] or the electrode voltage [32], [34], and applying closed-loop feedback to adjust the supply voltage), which itself consumes power. Such systems with dynamic voltage supplies are useful for accommodating electrode impedance variation after implantation and adapting to different stimulus currents. Fig. 3 shows that for a given $t_{\text {stim }}$, a small stimulus current (red curve in the figure) requires a smaller supply voltage than a large stimulus current (black curve in the figure). An alternative approach used in the design example (Sections III-V) adjusts the supply voltage monitored at the end of the stimulation pulse to be just above the peak electrode voltage. It consumes only a fraction of the power required for continuous electrode monitoring. Table II lists different stimulator ASICs that employ dynamic supply voltages.

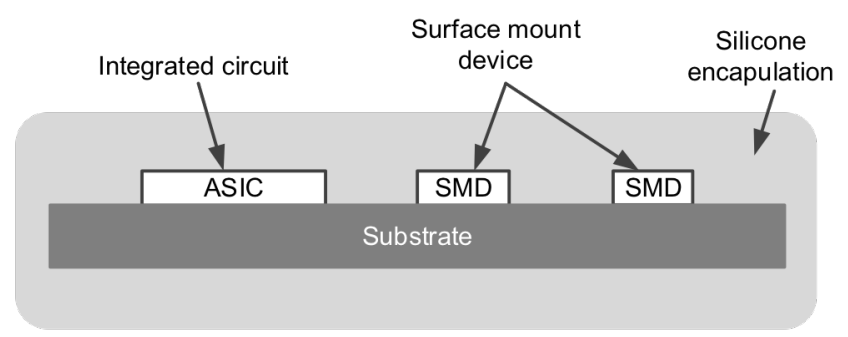

(a)

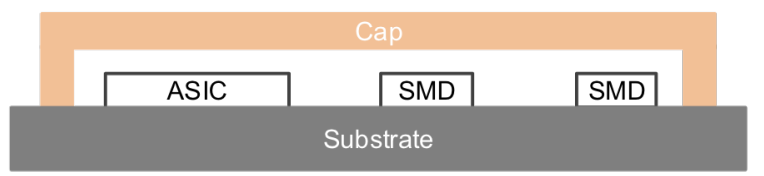

(b)

Fig. 4. Protection methods against water ingress: (a) silicone encapsulation; (b) hermeticic micropackage.

\section{Reliability of Small Implants}

As the size of implants reduces engineering challenges arise, requiring additional tests for monitoring the integrity of the ASIC.

1) Heat Dissipation: Conventional implanted devices, such as pacemakers, are relatively large. The electronic circuits are usually enclosed in a metal casing. Nowadays, it is common practice to use silicon microchip technology to integrate as much implant electronics as possible. The final size of the ASIC ranges from a couple of $\mathrm{mm}^{2}$ to tens of $\mathrm{mm}^{2}$. The power dissipation density from the surface of the ASIC becomes higher as implanted devices become smaller. Animal studies have shown that a maximum of $40 \mathrm{~mW} / \mathrm{cm}^{2}$ chronic heat flux can be tolerated for implantable devices, as this has been shown to lead to less than $1{ }^{\circ} \mathrm{C}$ temperature increase of the surrounding tissue [35]. Chronic temperature increases larger than this can harm the tissue [36], [37], [38]. A temperature sensor on the same ASIC as the stimulator circuits can help to 


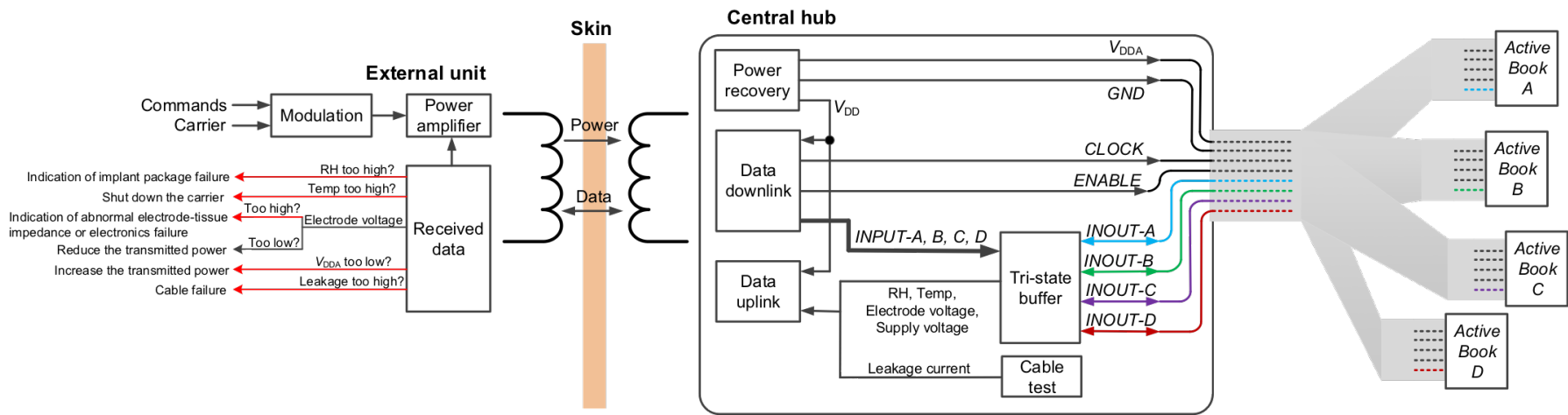

Fig. 5. Stimulation system using Active Books.

monitor the implant temperature for safety purposes.

2) Hermeticity of Implant Package: Implantable devices are surrounded by body fluid which is a corrosive environment and electronic circuits need to be protected by either a hermetic package or encapsulation, as shown in Fig. 4. Encapsulation protects the electronics with a conformal layer such as silicone rubber. Although the method is low cost and can be very reliable by careful design, there is no reported data on its effectiveness in protecting silicon microchips. Hermetic packaging is a much more popular method [39]. By maintaining them in a cavity [between the cap and substrate, see Fig. 4(b)] it isolates the electronic components from the body fluids. The hermeticity of a package is commonly evaluated by a helium leak test. Although effective in testing the package of large implants (internal volume $>1 \mathrm{~cm}^{3}$ ), it suffers from limited sensitivity when testing micrometervolume packages, which is currently the case for chip-scale implants [40]. While it may still be possible to produce sealed cavities that remain dry for decades inside the body, its hermeticity cannot be verified using conventional gas tracer methods. The introduction of humidity sensors inside micropackages makes it possible to continuously monitor the internal relative humidity. If the recorded humidity inside the package is higher than the predefined critical value, it indicates failure of the implant package.

\section{Design Example - System Design}

This design example is targeting stimulation of the lumbosacral nerve roots in the human cauda equina.. The goal is to develop an implant for restoring lower-body function to patients with paraplegia after severe spinal cord injury; for example, to enable exercising such as cycling and rowing, to control the bladder and to improve bowel evacuation. Tripolar electrode books are used to stimulate nerve roots/rootlets in the cauda equina (each root comprises fibres from several rootlets that emerge from the spinal cord). The leg muscles are innervated from levels L2 to S2, and as discussed in Section II-A, a distributed stimulating system of up to 96 channels is required. The design example employs Active Books [10], [18]. Each Active Book has an embedded ASIC. It provides stimulation pulses to the (book) electrodes and measures temperature, humidity and peak electrode voltage, which are
TABLE III

CORRESPONDING Voltages DuRING THE CABLE TEST

\begin{tabular}{|c|c|c|c|c|c|}
\hline Step & $V_{\text {DDA }}$ & $G N D$ & CLOCK & $E N A B L E$ & INPUT-A \\
\hline 1 & $18 \mathrm{~V}$ & 0 & 0 & 0 & 0 \\
\hline 2 & 0 & 0 & $5 \mathrm{~V}$ & 0 & 0 \\
\hline 3 & 0 & 0 & 0 & $5 \mathrm{~V}$ & 0 \\
\hline 4 & 0 & 0 & 0 & 0 & $5 \mathrm{~V}$ \\
\hline
\end{tabular}

TABLE IV

RELATION BETWEEN PEAK EleCtRode Voltage AND UPDATED $V_{\text {DDA }}$

\begin{tabular}{|c|l|}
\hline $\begin{array}{l}\text { Condition } \\
\text { (range of peak electrode voltage) }\end{array}$ & Updated $\boldsymbol{V}_{\text {DDA }}$ \\
\hline Eld $>17.25 \mathrm{~V}$ & $0 \mathrm{~V}$ \\
\hline $17.25 \mathrm{~V}>$ Eld $>15.75 \mathrm{~V}$ & $18 \mathrm{~V}$ \\
\hline $15.75 \mathrm{~V}>$ Eld $>14.25 \mathrm{~V}$ & $16.5 \mathrm{~V}$ \\
\hline $14.25 \mathrm{~V}>$ Eld $>12.75 \mathrm{~V}$ & $15 \mathrm{~V}$ \\
\hline $12.75 \mathrm{~V}>$ Eld $>11.25 \mathrm{~V}$ & $13.5 \mathrm{~V}$ \\
\hline $11.25 \mathrm{~V}>$ Eld $>9.75 \mathrm{~V}$ & $12 \mathrm{~V}$ \\
\hline $9.75 \mathrm{~V}>$ Eld $>8.25 \mathrm{~V}$ & $10.5 \mathrm{~V}$ \\
\hline $8.25 \mathrm{~V}>$ Eld $>6.75 \mathrm{~V}$ & $9 \mathrm{~V}$ \\
\hline $6.75 \mathrm{~V}>$ Eld & $7.5 \mathrm{~V}$ \\
\hline
\end{tabular}

used for safety monitoring. As a proof of concept, a 16channel stimulation system using four Active Books is discussed. The number of supported channels can be increased with minimal change at the central hub, by adding more Active Books.

Fig. 5 shows the block diagram of the stimulation system in which power is supplied to the implant via an inductive link. The implant part comprises a central hub and four Active Books, each with an identical ASIC intimately connected. At the external unit, different commands can be deployed which either initiate desirable stimulation functions or instruct the integrated sensors to measure critical conditions at the Active Book. The command information is modulated on to a $10 \mathrm{MHz}$ carrier, which drives a class-D power amplifier. The supply voltage for the class-D amplifier is adjustable according to the feedback information from the supply-voltage sensor at the ASIC.

At the central hub, the power recovery unit delivers two dc supply voltages, a low voltage $V_{\mathrm{DD}}$ for driving the electronics at the central hub and a high voltage $V_{\mathrm{DDA}}$ for driving the four ASICs. The amplitude of $V_{\mathrm{DDA}}$ is managed by the central hub based on the feedback information from the peak-electrodevoltage sensor in the ASIC. The data downlink demodulates 


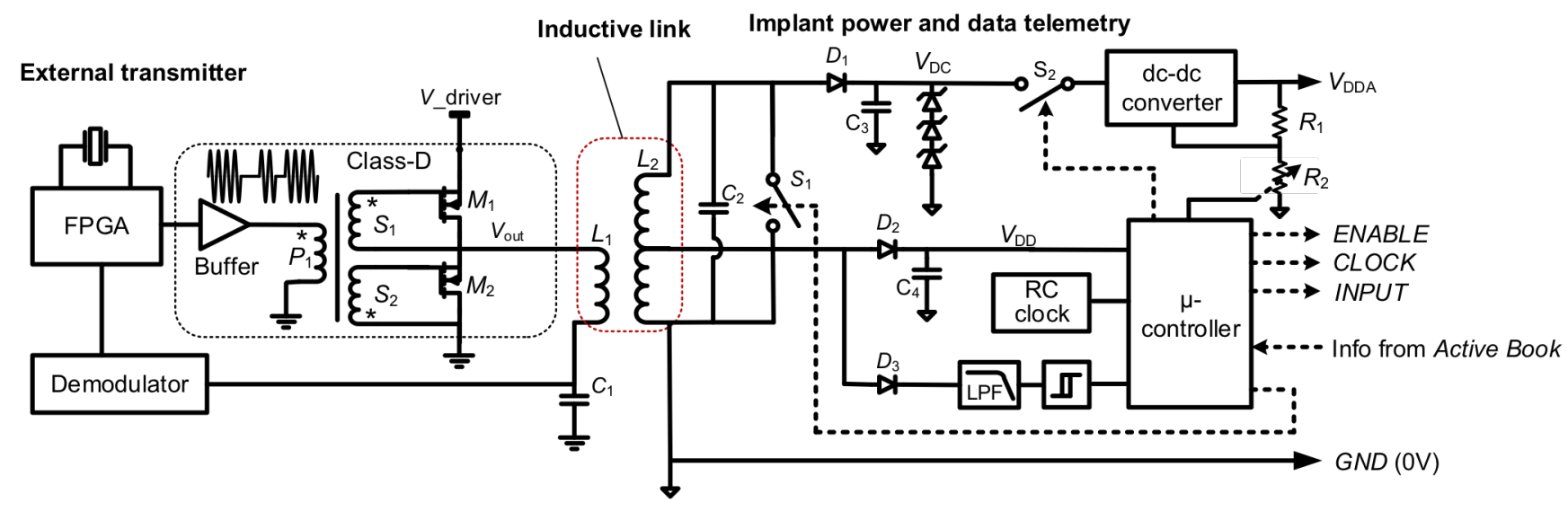

Fig. 6. The implant power and data telemetry.

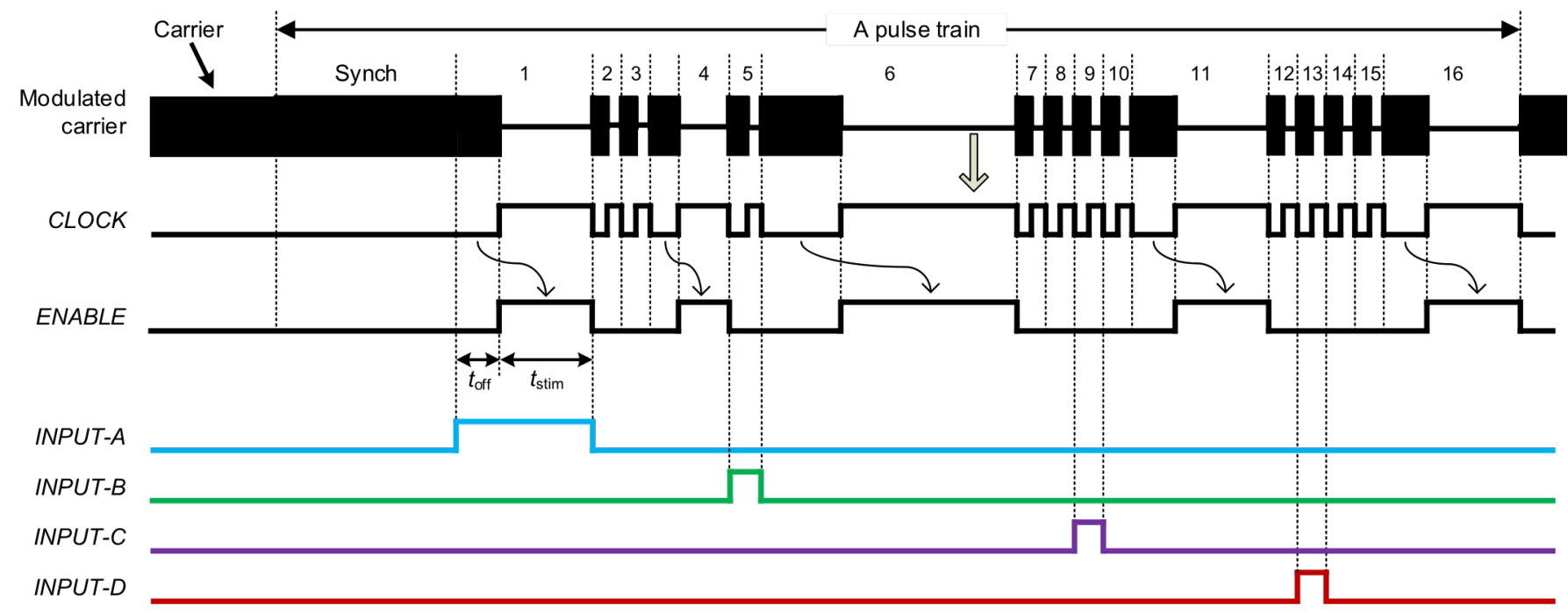

Fig. 7. Demodulation of $C L K, E N A B L E$, and INPUT-A, INPUT-B, INPUT-C and INPUT-D from the modulated carrier over one pulse train.

the command information from the carrier and recovers one $C L O C K$, one ENABLE and $n$ INPUT signals, where $n$ depends on the number of Active Books driven by the central hub. Each ASIC is driven by a 5 -wire cable ( $V_{\mathrm{DDA}}, G N D, C L O C K$, ENABLE and INPUT). Except for the INPUT which is book specific, the remaining four signals are common to the other Active Books.

For forward and continuous operation of the ASIC, the proposed stimulation system must pass several tests as detailed in the following subsections.

\section{A. Cable Test}

Before any valid signals are sent to the ASIC, the central hub tests the leakage current of the cable of each Active Book. Table III shows the procedure for testing the cable of Active Book A. The signals $V_{\mathrm{DDA}}, C L O C K, E N A B L E$, and INPUT-A are turned high one at a time and the dc current between any of the two wires is measured. The same procedure can be repeated for testing cables of other Active Books. During the cable test, the ASIC is held in the quiescent mode, consuming very small current (nanoamperes). A high measured dc current indicates failure(s) at the cable (such as insulation failure) or at the ASIC (such as introducing a low-impedance path between wires). All cables need to pass the test before any one of the Active Books connected can be used.

\section{B. ASIC Status Test}

In addition to taking information from the central hub, the ASIC sends operating status information for monitoring purposes to the central hub. The INPUT- $X$ wire is bidirectional (see INOUT-X in Fig. 5). Information to the hub includes the temperature of the ASIC, the relative humidity inside the ASIC's hermetic micropackage, the peak electrode voltage of a stimulating electrode, and the current $V_{\mathrm{DDA}}$ voltage, all measured by the sensors on the ASIC. The sensed information triggers appropriate actions at either the central hub unit or the external unit.

If the surface temperature of the ASIC in a given Active Book is higher than $41{ }^{\circ} \mathrm{C}$, it will be shut down immediately and cannot be reactivated for thirty minutes. To shut down the ASIC, all five wires in the cable are switched off (turned to 0 $\mathrm{V})$. After that, as long as the INPUT wire remains low, the ASIC is kept in its quiescent mode, consuming negligible current, independent of the signals at $V_{\mathrm{DDA}}, G N D, C L O C K$ and $E N A B L E$. A constant low at the INPUT wire after $V_{\mathrm{DDA}}$ has been turned on will isolate the ASIC in question, having no 


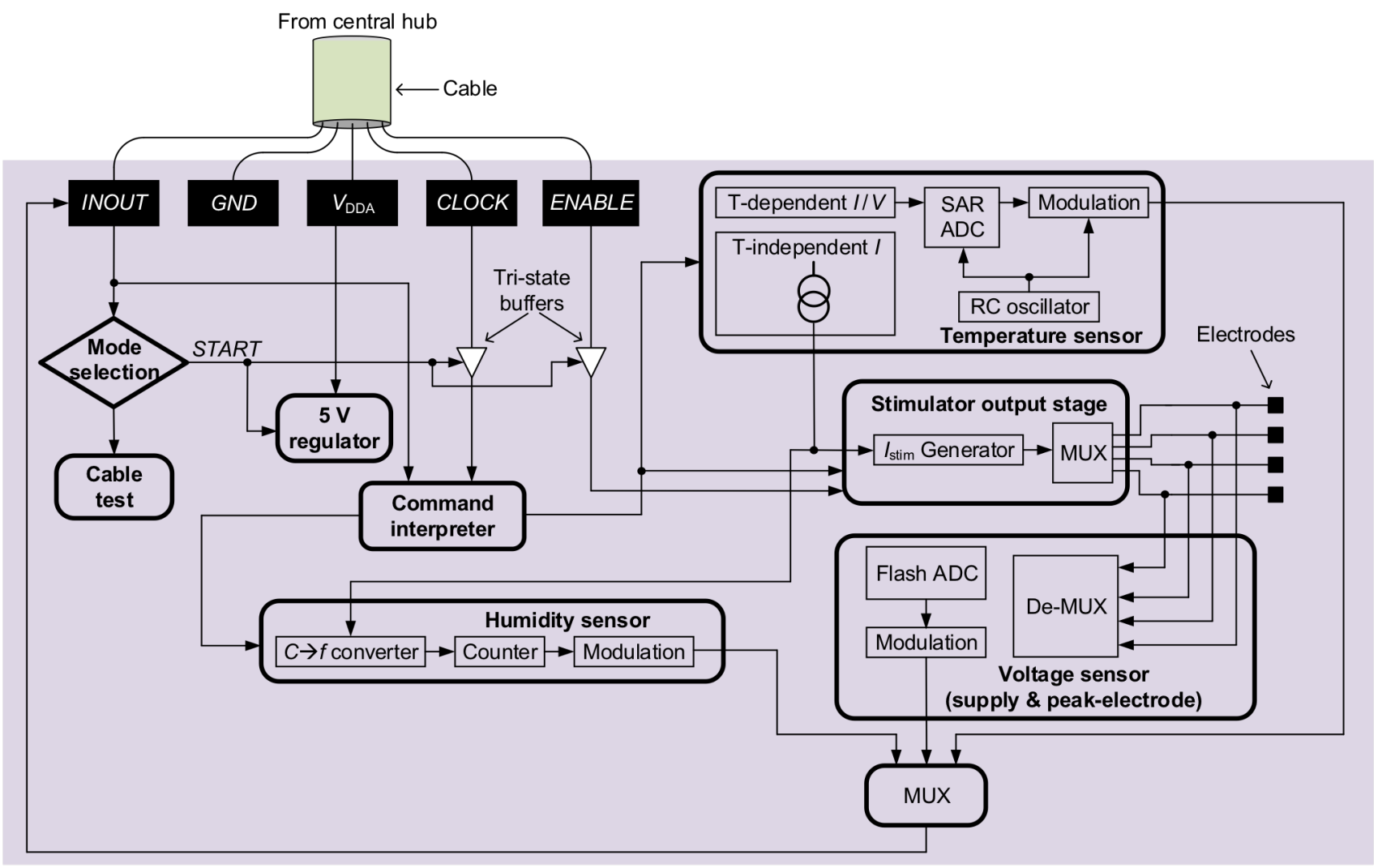

Fig. 8. Functional block diagram of the ASIC for Active Books.

further impact on heat dissipation.

If the relative humidity of the ASIC micropackage inside an Active Book is close to the predefined critical value (defined as the humidity beyond which the corrosion rate is unacceptable, significantly reducing the reliability of the device) the sensor information will be transmitted to the external unit, alerting the user/manufacturer to the failed or soon-to-fail micropackage.

Once the central hub receives the information on the peak electrode voltage of a stimulating anode, it reissues a new supply voltage should the peak electrode voltage be significantly different from the current $V_{\mathrm{DDA}}$. Table IV shows the updated $V_{\mathrm{DDA}}$ for the electrode voltage (Eld) ranges. A lower supply voltage helps to save power, which would otherwise be wasted across the current generator. As a safety feature, if the peak electrode voltage is more than $17.25 \mathrm{~V}$, it will be considered as dangerous as it is too close to the maximum possible $V_{\mathrm{DDA}}$, i.e., $18 \mathrm{~V}$. Possible causes include prolonged dc current which saturates the electrode to a nearthe-supply voltage. The ASIC will subsequently be shut down, avoiding further damage to the electrode-tissue interface.

After implantation, there may be misalignment between the primary and secondary coils and a change of distance between the two coils, causing $V_{\mathrm{DDA}}$ variation due to change in coupling of the inductive link. The current $V_{\mathrm{DDA}}$ can be sensed by the supply-voltage sensor on the ASIC. The step sizes are the same as the peak-electrode-voltage sensor. The information is sent to the external unit, and the supply voltage for the power amplifier is adjusted accordingly, hence more or less power can be delivered to the central hub to generate an optimum $V_{\mathrm{DDA}}$.

\section{Design EXAmple - CirCuit Design}

\section{A. Telemetry}

Fig. 6 shows the implementation of the inductive link for sending the data and power transcutaneously from the external unit to the central hub. Components $L_{1}, C_{1}$ and $L_{2}, C_{2}$ are tuned to $10 \mathrm{MHz}$. Fig. 7 shows the transmitted signal over the telemetry using on-off keying (OOK) modulation. When no data is sent (i.e., sending all ' $0 \mathrm{~s}$ '), the carrier signal remains continuous, charging up capacitors $C_{3}$ and $C_{4}$. When a ' 1 ' needs to be sent, the carrier stops for the duration of the ' 1 '. The advantage of OOK is that its modulator and demodulator are relatively easy to implement compared with other shift keying methods, such as frequency shift keying (FSK) and binary phase shift keying (BPSK). The transmission of power is continuous as long as the carrier is on. The transfer of data has little impact on the overall transmitted power if the data rate is low. Two dc voltages, $V_{\mathrm{DC}}$ and $V_{\mathrm{DD}}$ are recovered at the full-length and mid-point of the secondary coil after rectification. $V_{\mathrm{DC}}$ is protected by three series $2.4 \mathrm{~V}$ Zener diodes (NXP, BZV55-B2V4) as a shunt regulator. $V_{\mathrm{DD}}$ is a low voltage used for driving the microcontroller and other peripheral circuits in the central hub. $V_{\mathrm{DC}}$ connects to a dc-dc converter (LT1615 by Linear Technology), which provides the high voltage supply, $V_{\mathrm{DDA}}$, to the ASIC. $V_{\mathrm{DDA}}$ is defined by 


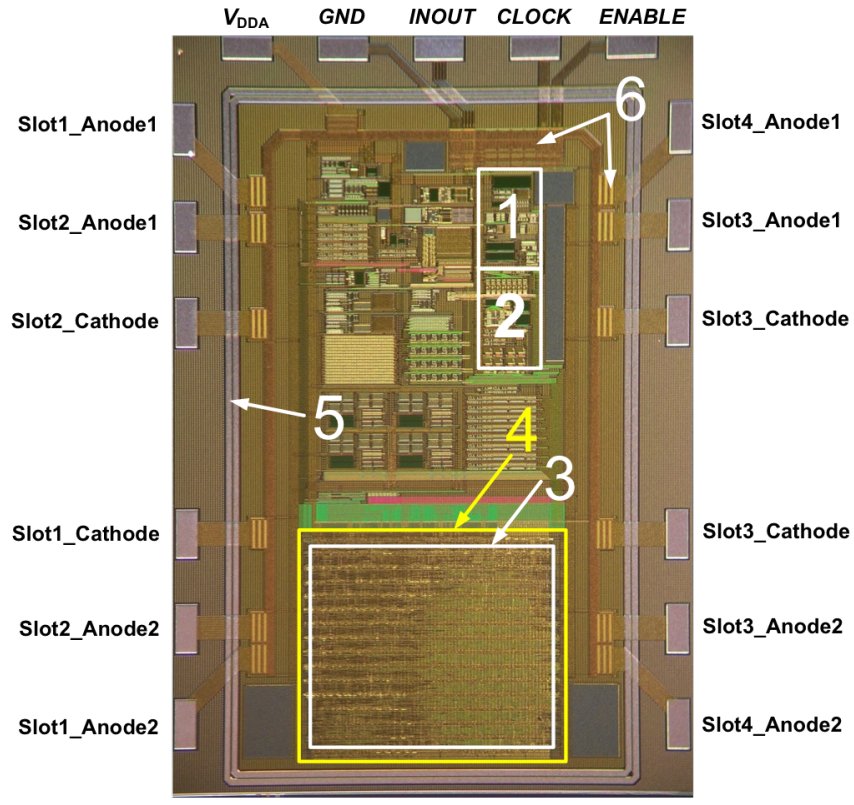

Fig. 9. Die photo of the ASIC. The marked areas show; 1: temperature sensor; 2: voltage sensor; 3 : capacitive humidity sensor; 4: digital circuits, 5: seal ring for micropackaging, and 6: ESD for IOs.

$$
V_{\mathrm{DDA}}=1.23\left(\frac{R_{1}}{R_{2}}+1\right)
$$

The amplitude of $V_{\mathrm{DDA}}$ is set by the microcontroller by choosing a suitable resistor ratio $R_{1} / R_{2}$.

To demodulate the data from the carrier, the microcontroller first checks whether the synchronization word matches the expectation (101101110111101). If not, the data will not be utilized. Each digit in the synchronization word lasts for one cycle (i.e., $1 \mu \mathrm{s}$ ) and can be sampled by a simple detector circuit whose frequency does not need to be accurate. If the synchronization word matches, the microcontroller recovers INOUT, CLOCK and ENABLE for driving the ASICs in the Active Books. CLOCK is recovered by passing the $T X$ signal through an envelope detector (LP filter) and then inverted. The shortest interval between pulses (i.e., the off phase on the CLOCK line) is $10 \mu \mathrm{s}$, which is more than twice that of the longest continuous ' $1 \mathrm{~s}$ ' or ' $0 \mathrm{~s}$ ' in the synchronization word. The ENABLE signal is recovered by monitoring the off phase of the pulses on the CLOCK line. If the off phase is longer than $30 \mu \mathrm{s}$, the following on phase becomes ENABLE pulses. The generation of the INOUT series signals is straight forward as they turn high at the first, fifth, ninth and thirteenth pulse of the $C L O C K$ line, respectively.

A significant benefit of the proposed communication protocol is that it does not need an accurate reference clock for sampling the data stream as all the timing information is built into the data signals. At the ASIC, all events are triggered by the rising or falling edge of the data wires. Hence, there is no need for a phase locked loop (PLL) circuit or a crystal to provide an accurate sampling clock. The duration of the stimulus pulse for each channel is defined by the corresponding pulse on the ENABLE line.
TABLE IV

ASIC FeAtures AND MEASUREd PERformance Summary

\begin{tabular}{|l|l|}
\hline Parameter & Value \\
\hline Technology & $0.6 \mu \mathrm{m} \mathrm{HV} \mathrm{CMOS}$ \\
\hline Supply voltage & $18 \mathrm{~V}$ \\
\hline Die size & $6.3 \times 4.3 \mathrm{~mm}^{2}$ \\
\hline IO pads & $2 \times$ power, $3 \times$ data, $12 \times$ electrodes \\
\hline Channels & 4 tripole \\
\hline $\begin{array}{l}\text { Stimulation } \\
\quad \text { - Stimulus current amplitude } \\
\text { - Anode current ratio adjustment } \\
\text { - Stimulus pulse duration }\end{array}$ & $1 \mathrm{~mA}, 4 \mathrm{~mA}$ or $8 \mathrm{~mA}$ \\
\hline Temperature sensor resolution & $2 \mu \mathrm{s}$ in steps of $2 \%$ \\
\hline Humidity sensor resolution & $0.12{ }^{\circ} \mathrm{C}$ \\
\hline $\begin{array}{l}\text { Voltage sensor } \\
\text { - Detectable range }\end{array}$ & $\sim 1 \% \mathrm{RH}$ \\
- Resolution & $0-18 \mathrm{~V}$ \\
\hline
\end{tabular}

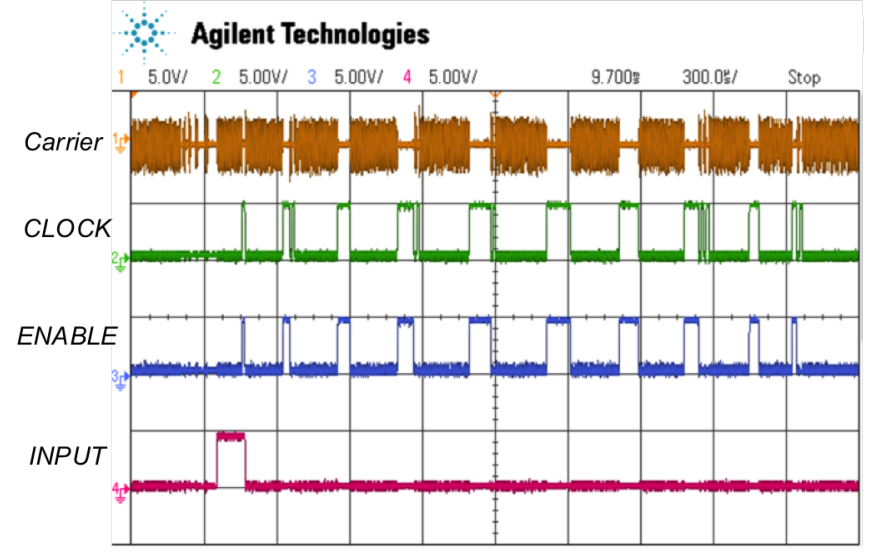

Fig. 10. Demodulation of CLOCK, ENABLE and INPUT signals from the RF carrier.

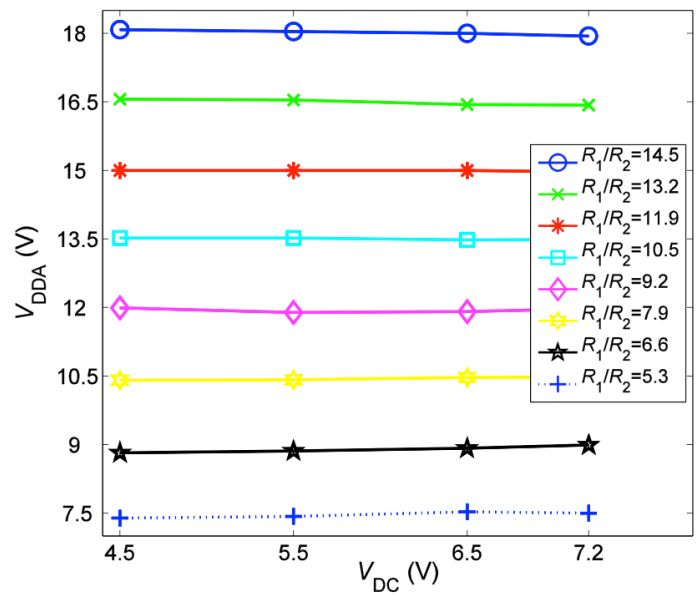

Fig. 11. $V_{\mathrm{DDA}}$ vs. $V_{\mathrm{DC}}$ for the dc-dc converter at different settings.

\section{B. ASIC Functionality}

Fig. 8 shows the block diagram of the ASIC for the Active Books. It works in the quiescent mode during the cable test and can be woken up by sending a pulse on the INOUT line while $V_{\mathrm{DDA}}$ is high. The ASIC drives four tripoles. A tripolar electrode configuration contains three electrodes: a central 


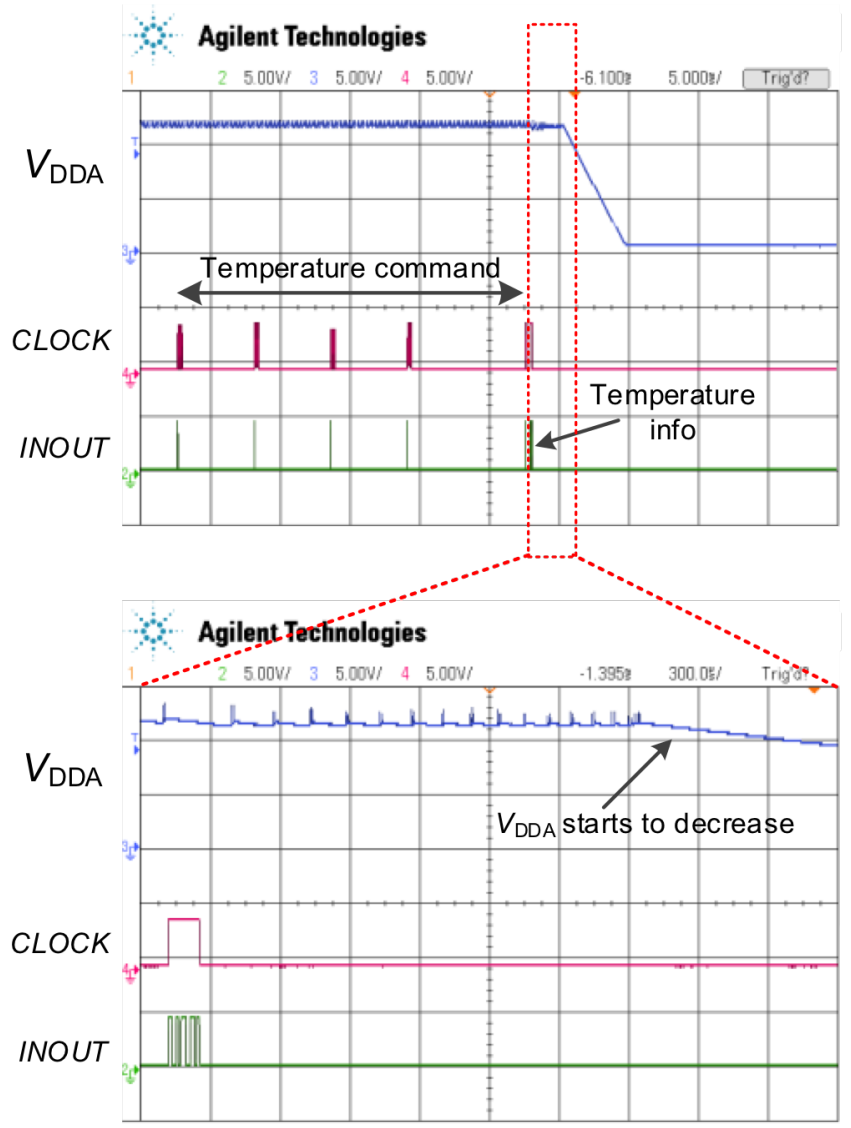

Fig. 12. Response of $V_{\mathrm{DDA}}$ to temperature information.

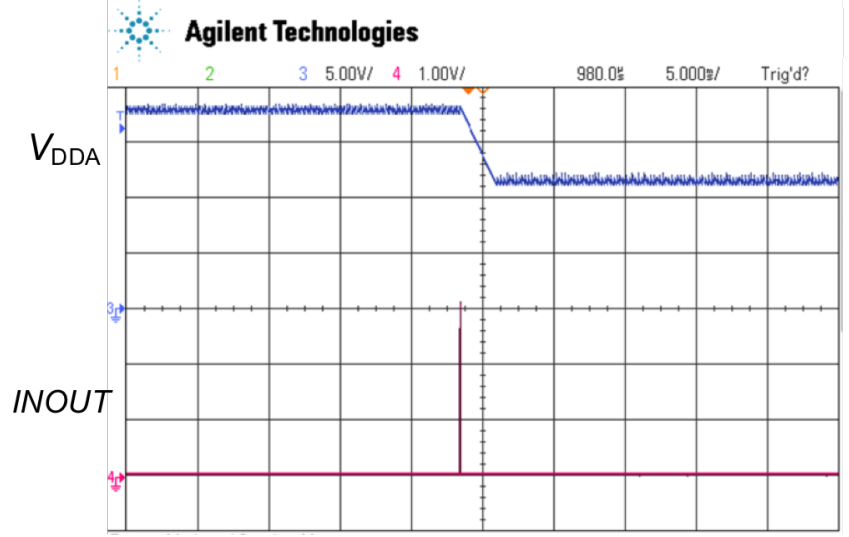

Fig. 13. Response of $V_{\mathrm{DDA}}$ to a peak electrode voltage between $9.75 \mathrm{~V}$ and $11.25 \mathrm{~V}$.

cathode flanked by two outer anodes. The stimulus current which splits between two anodes can be adjusted to $0 \mathrm{~mA}$, $1 \mathrm{~mA}, 4 \mathrm{~mA}$ and $8 \mathrm{~mA}$. The current difference between two anodes can be programmed to $\pm 20 \%$ in steps of $2 \%$. There are four sensors on the ASIC, which can measure temperature, relative humidity, peak electrode voltage of any anode in a Book, and the current supply voltage. The ASIC is a development of the design described in [10] with additional functionality and sensors to enable measurement of temperature, humidity and peak electrode voltage for monitoring purposes and safety.

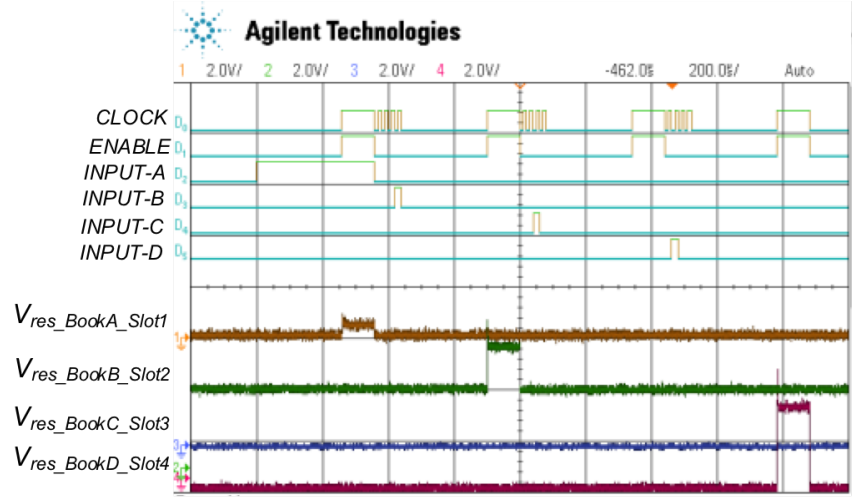

Fig. 14. Stimulus currents at corresponding slots in different books.

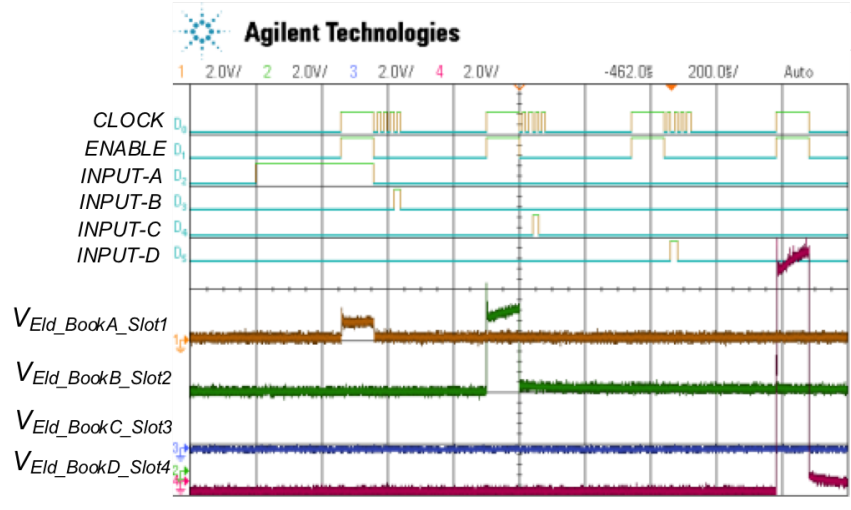

Fig. 15. Anode-cathode voltages of corresponding slots in different books.

\section{Design Example - Measured Results}

The ASIC was implemented using XFAB's $0.6-\mu \mathrm{m}$ HV CMOS process. The ASIC has a total of 17 input-outputs (IOs) laid out in a predefined pattern for easy connection to the implant cable (containing 5 wires) and electrodes (3 electrodes per tripole $\times 4$ tripoles $=12$ ). Fig. 9 shows the die photo of the ASIC and Table V lists some of its features and measured performance. The central hub was built on a printed circuit board using off-the-shelf components. Four Active Books (each with an ASIC connected to a Book) were connected to the central hub via medical grade Copper cable.

Fig. 10 shows the demodulation of INPUT-A, CLOCK and ENABLE from the RF carrier. Fig. 11 shows the output voltage of the dc-dc converter which is independent of $V_{\mathrm{DC}}$. $V_{\text {DDA }}$ can be set to $18 \mathrm{~V}, 16.5 \mathrm{~V}, 15 \mathrm{~V}, 13.5 \mathrm{~V}, 12 \mathrm{~V}, 10.5 \mathrm{~V}$, $9 \mathrm{~V}$ and $7.5 \mathrm{~V}$ by the microcontroller. The ratio $R_{1} / R_{2}$ used in the system is slightly higher than the theoretical calculation in (3). This is due to the limited power from the secondary coil that can be made available to the input of the dc-dc converter.

Fig. 12 shows the response of the system when the hub receives high temperature information from an ASIC. To simulate the high-temperature condition, the ASIC was placed in an environment temperature chamber, which was set to $41^{\circ} \mathrm{C}$. The hub was placed outside the chamber and had an ambient temperature of $17^{\circ} \mathrm{C}$. Fig. 12 shows the central hub supplies active $V_{\mathrm{DDA}}, C L O C K$ and INOUT signals before 
being told the surface temperature of the ASIC. After sending a temperature-enquiry command to the ASIC and detecting its surface temperature at $41{ }^{\circ} \mathrm{C}$, the central hub shuts down all five wires.

Fig. 13 shows the response of the system to the low anode voltage. The $V_{\mathrm{DDA}}$ started with $18 \mathrm{~V}$. Then a Measure_Slot1_Anode1 command was sent to the ASIC and it returned with ' 1101011 ' meaning the peak anode voltage was between $9.75 \mathrm{~V}$ and $11.25 \mathrm{~V}$. The microcontroller reacted accordingly and instructed the dc-dc converter to provide a level of possible supply voltage (which was just above $12 \mathrm{~V}$ in this case).

Figs. 14 and 15 show the stimulation performance of the system with electrodes in physiological saline solution. Among 16 available channels, Slot 1 of Book A, Slot 2 of Book $B$, Slot 3 of Book $C$ and Slot 4 of Book D were chosen for stimulation. Before the stimulation, the amplitude of the stimulus current on Book $A-D$ was programmed to $1 \mathrm{~mA}$, $4 \mathrm{~mA}, 0 \mathrm{~mA}$ and $8 \mathrm{~mA}$, respectively. The width of the stimulation pulse, $100 \mu \mathrm{s}$ in Fig. 14, was set by the width of the corresponding pulse on the ENABLE line. The stimulus current in each channel was monitored by a floating-input differential probe (Pico Technology TA044) measuring the voltage across a $420 \Omega$ resistor placed in series with the cathode electrode. Fig. 15 shows the voltage between the cathode and one of the anodes in each stimulating channel. As evident from the figure, there is no noticeable crosstalk between different channels.

\section{CONCLUSION}

Recent advances in scalable implantable stimulation systems using networked ASICs for use in applications with a large number of electrodes have been reviewed. As an example the detailed design has been presented of an implantable neurostimulation system for restoring lower limb functions in paraplegics after spinal cord injury. It comprises four Active Books, each with an ASIC intimately connected to twelve electrodes, an implanted central hub for controlling the Active Books, and an inductively coupled power and data telemetry. In addition to stimulation, the ASIC monitors temperature, humidity and electrode voltage levels. The information from the sensors on the ASIC and cable leakage current tests, ensure that the operation of the implant never exceeds prescribed safety limits. The implant architecture is scalable and a larger number of stimulating channels can be accommodated by using more Active Books.

\section{REFERENCES}

[1] J. H. Moe and H. W. Post, "Functional electrical stimulation for ambulation in hemiplegia," J. Lancet, vol. 82, pp. 285-288, Jul. 1962.

[2] K. Arabi and M.A. Sawan, "Electronic design of a multichannel programmable implant for neuromuscular electrical stimulation," IEEE Trans. Rehabil. Eng., vol. 7, no. 2, pp. 204-214, Jun. 1999.

[3] K. D. Wise, A. M. Sodagar, Y. Ying, M. N. Gulari, G. E. Perlin, and K. Najafi, "Microelectrodes, microelectronics, and implantable neural microsystems," Proc. IEEE, vol. 96, no. 7, pp. 1184-1202, Jul. 2008.

[4] F.-G. Zeng; S. Rebscher, W. Harrison, X. Sun and H. Feng, "Cochlear implants: System design, integration, and evaluation," IEEE Rev. Biomed. Eng., vol.1, pp.115-142, 2008.
[5] E. Noorsal, K. Sooksood, H. Xu, R. Hornig, J. Becker, and M. Ortmanns, "A neural stimulator frontend with High-Voltage compliance and programmable pulse shape for epiretinal implants," IEEE J. SolidState Circuits, vol. 47, no. 1, pp. 244-256, Jan. 2012.

[6] R. A. Fernandes, B. Diniz, R. Ribeiro, and M. Humayun, "Artificial vision through neuronal stimulation," Neurosci. Lett., vol. 519, no. 2, pp. 122-128, Jun. 2012.

[7] D. M. Merfeld and R. F. Lewis, "Replacing semicircular canal function with a vestibular implant," Curr. Opin. Otolaryngology Head Neck Surg., vol. 20, no. 5, pp. 386-392, Oct. 2012.

[8] D. Jiang A. Demosthenous, T. Perkins, X. Liu, and N. Donaldson, "A stimulator ASIC featuring versatile management for vestibular prostheses," IEEE Trans. Biomed. Circuits Syst., vol. 5, no. 2, pp. 147159, Apr. 2011.

[9] D. Jiang, D. Cirmirakis, and A. Demosthenous, "A vestibular prosthesis with highly-isolated parallel multichannel stimulation," in Biomedical Circuits and Systems, IEEE Trans. Biomed. Circuits Syst., vol. 9, no. 1, pp. 124-137, Feb. 2015.

[10] X. Liu, A. Demosthenous, A. Vanhoestenberghe, D. Jiang, and N. Donaldson, "Active Books: The design of an implantable stimulator that minimizes cable count using integrated circuits very close to electrodes," IEEE Trans. Biomed. Circuits and Syst., vol. 6, no. 3, pp. 216-227, Jun. 2012.

[11] V. Giagka, C. Eder, N. Donaldson, and A. Demosthenous, "An implantable versatile electrode-driving ASIC for chronic epidural stimulation in rats," IEEE Trans. Biomed. Circuits Syst., vol. 9, no. 3, pp. 387-400, Jun. 2015.

[12] S. Harkema, Y. Gerasimenko, J. Hodes, J. Burdick, C. Angeli, Y. Chen $\mathrm{Y}$, et al., "Effect of epidural stimulation of the lumbosacral spinal cord on voluntary movement, standing, and assisted stepping after motor complete paraplegia: a case study," Lancet, vol. 377, no. 9781, pp. 1938-1947, Jun. 2011.

[13] M. Ortmanns, A. Rocke, M. Gehrke, and H. J. Tiedtke, "A 232-channel epiretinal stimulator ASIC," IEEE J. Solid-State Circuits, vol. 42, no. 12, pp. 2946-2959, Dec. 2007.

[14] R. Shulyzki, K. Abdelhalim, A. Bagheri, M. T. Salam, C. M. Florez, J. L. Perez Velazquez, P. L. Carlen, R. Genov, "320-Channel Active Probe for High-Resolution Neuromonitoring and Responsive Neurostimulation," IEEE Trans. Biomed. Circuits and Syst., vol. 9, no. 1, pp. 34-49, Feb. 2015.

[15] T. Nguyen, S. Zupancic, and D. Lie, "Engineering challenges in cochlear implants design and practice," IEEE Circuits and Syst. Mag., vol. 12, no. 4, pp. 47-55, Fourth quarter 2012.

[16] C.-C. Wang, T.-C. Sung, Y.-H. Wu, C.-H. Hsu, and D. Shmilovitz, "A reconfigurable 16-channel HV stimulator ASIC for Spinal Cord Stimulation systems," in Proc. 2012 IEEE Asia Pacific Conf. Circuits and Syst., pp. 300-303, 2012.

[17] T. Guenther, N. H. Lovell, and G. J. Suaning, "Bionic vision: System architectures: A review," Expert Rev. Med. Devices, vol. 9, no. 1, pp. 33-48, Jan. 2012.

[18] N. Donaldson, A. Vanhoestenberghe, X. Liu, N. Saeidi, A. Demosthenous, and M. Schuettler, "Active Books: A practical way to increase the number of stimulation channels for FES after SCI?," in Proc. 15th Annu. Int. FES Soc. Conf., 2010.

[19] J. M. Henderson, C. M. Schade, J. Sasaki, D. L. Caraway, and J. C. Oakley, "Prevention of mechanical failures in implanted spinal cord stimulation systems," Neuromodulation., vol. 9, no. 3, pp. 183-191, Jul. 2006.

[20] G. S. Brindley, "The first 500 sacral anterior root stimulators: implant failures and their repair," Paraplegia, vol. 33, no. 1, pp. 5-9, Jan. 1995.

[21] V. Heidecke, N. G. Rainov, and W. Burkert, "Hardware failures in spinal cord stimulation for failed back surgery syndrome," Neuromodulation. vol. 3, no. 1, pp. 27-30, Jan. 2000.

[22] M. Sivaprakasam, W. Liu, G. Wang, J. D. Weiland, and M. S. Humayun, "Architecture tradeoffs in high-density microstimulators for retinal prosthesis," IEEE Trans. Circuits Syst. I: Reg., vol. 52, no. 12, pp. 2629-2641, Dec. 2005.

[23] M. Ghovanloo and K. Najafi, "A modular 32-site wireless neural stimulation microsystem," IEEE J. Solid-State Circuits, vol. 39, no. 12, pp. 2457-2466, Dec. 2004.

[24] M. Ghovanloo and K. Najafi, "A wireless implantable multichannel microstimulating system-on-a-chip with modular architecture," IEEE Trans. Neural Syst. Rehabil. Eng., vol. 15, no. 3, pp. 449-457, Sep. 2007. 
[25] T. Noda, K. Sasagawa, T. Tokuda, Y. Terasawa, H. Tashiro, H. Kanda, T. Fujikado, and J. Ohta, "Smart electrode array device with CMOS multi-chip architecture for neural interface," Electronics Letters, vol. 48, no. 21 , pp. $1328-1329$, Oct. 2012.

[26] P. Gad, J. Choe, M. S. Nandra, H. Zhong, R. R. Roy, Y.-C. Tai, and V. R. Edgerton, "Development of a multi-electrode array for spinal cord epidural stimulation to facilitate stepping and standing after a complete spinal cord injury in adult rats," J. Neuroeng. Rehabil, vol. 10, no. 2, pp. 1-17, Jan. 2013.

[27] M. A. Meza-Cuevas, D. Schroeder, and W. H. Krautschneider, "A scalable 64 channel neurostimulator based on a hybrid architecture of current steering DAC," Proc. 2014 Middle East Conf. Biomed. Eng. (MECBME), pp. 111-114, 17-20 Feb. 2014.

[28] A. M. Sodagar, G. E. Perlin, Y. Yao; K. Najafi, and K. D. Wise, "An implantable 64-channel wireless microsystem for single-unit neural recording," IEEE J. Solid-State Circuits, vol. 44, no. 9, pp. 2591-2604, Sep. 2009.

[29] M. N. van Dongen and W. A. Serdijn, "A power-efficient multichannel neural stimulator using high-frequency pulsed excitation from an unfiltered dynamic supply," IEEE Trans. Biomed. Circuits Syst., DOI: 10.1109/TBCAS.2014.2363736.

[30] I. Williams and T. G. Constandinou, "An energy-efficient, dynamic voltage scaling neural stimulator for a proprioceptive prosthesis," IEEE Trans. Biomed. Circuits Syst., vol. 7, no. 2, pp. 129-139, Apr. 2013.

[31] C.-Y. Lin; W.-L. Chen, and M.-D. Ker, "Implantable stimulator for epileptic seizure suppression with loading impedance adaptability," IEEE Trans. Biomed. Circuits Syst., vol. 7, no. 2, pp. 196-203, Apr. 2013.

[32] S. K. Arfin, and R. Sarpeshkar, “An energy-efficient, adiabatic Electrode stimulator with inductive energy recycling and feedback current regulation," IEEE Trans. Biomed. Circuits Syst., vol. 6, no. 1, pp. 1-14, Feb. 2012.

[33] U. Cilingiroglu and S. Ipek, "A Zero-Voltage Switching Technique for Minimizing the Current-Source Power of Implanted Stimulators," IEEE Trans. Biomed. Circuits Syst., vol. 7, no. 4, pp. 469-479, Aug. 2013.

[34] H.-M. Lee, H. Park, and M. Ghovanloo, "A power-efficient wireless system with adaptive supply control for deep brain stimulation," IEEE $J$. Solid-State Circuits, vol. 48, no. 9, pp. 2203-2216, Sept. 2013.

[35] C. R. Davies, F. Fukumura, K. Fukamachi, K. Muramoto, S. C. Himley, A. Massiello, J. F. Chen, and H. Harasaki, "Adaptation of tissue to a chronic heat load," ASAIO J., vol. 40, no. 3, pp. M514-7, Jul.-Sep. 1994.

[36] G. Lazzi, "Thermal effects of bioimplants," IEEE Eng. Med. Bio. Mag., vol. 24, no. 5, pp. 75-81, Sept. 2005.

[37] P. D. Wolf, "Thermal considerations for the design of an implanted cortical brain-machine interface (BMI)," in Indwelling Neural Implants: Strategies for Contending with the in vivo Environment. W. M. Reichert, Ed. Boca Raton, FL, USA: CRC Press, 2008.

[38] G. M. Saidel, C. R. Davies, E. H. Liu, and H. Harasaki, "Temperature and perfusion responses of muscle and lung tissue during chronic heatingin vivo," Med. Biol. Eng. Comput., vol. 39, no. 1, pp. 126-133, Jan. 2001.

[39] N. Saeidi, M. Schuettler, A. Demosthenous, and Donaldson N., "Technology for integrated circuit micropackages for neural interfaces, based on gold-silicon wafer bonding," J. Micromech. Microeng., vol. 23 , no. 7, p. 075021 , Jul. 2013.

[40] A. Vanhoestenberghe and N. Donaldson, "Corrosion of silicon integrated circuits and lifetime predictions in implantable electronic devices," J. Neural Eng., vol. 10, no. 3, p. 031002, 2013.

\section{Authors Biographies}

Xiao Liu is a Lecturer at the Department of Electronic and Electrical Engineering, University College London (UCL), UK. His main research interests include analog and mixed-signal circuit design for neuroprostheses, sensor design and wearable technologies. Liu has a Ph.D. degree from UCL (2009). He is a member of the Biomedical and Life Science Circuits and Systems Technical Committee of the IEEE Circuits and Systems Society.

Zhulin Zong is an Associate Research Fellow at the School of Electronic Engineering, University of Electronic Science and Technology of China (UESTC), China. His research interests are related to the design of digital integrated circuits for radar, communications, signal processing and bio-medical applications. Zong has a PhD from UESTC (2012).

Dai Jiang is a Research Associate at the Department of Electronic and Electrical Engineering, University College London (UCL), UK. His research interests include CMOS analog and mixed-signal integrated circuit design for biomedical applications. Jiang has a PhD degree from UCL (2009).

Bachir Bougaila is a research student in the Department of Electrical and Electronic Engineering, University College London (UCL), UK. His current research interest is the design of energy efficient implantable neurostimulators. Bougaila has a Masters degree in Microelectronics Systems Design from the University of Southampton, UK (2011).

Nick Donaldson is a Professor in the Department of Medical Physics and Bioengineering, University College London (UCL), UK. His research interests include the development of implanted devices that use natural nerve signals as inputs, especially for preventing incontinence, stimulators of nerve roots, the use of electrical stimulation for recreational exercise of paralyzed legs and methods to encourage functional neurological recovery after injury. Donaldson has a PhD degree from UCL (1990). 
Andreas Demosthenous is a Professor in the Department of Electronic and Electrical Engineering, University College London (UCL), UK, where he leads the Analog and Biomedical Electronics Group. He has published more than 200 articles in journals and international conference proceedings. His research interests include analog and mixed-signal integrated circuits for biomedical, sensor and signal-processing applications. Demosthenous has a PhD degree from UCL (1998). He is the Editor-in-Chief of the IEEE Transactions on Circuits and Systems I: Regular Papers, a Fellow of the Institution of Engineering and Technology (IET) and a Chartered Engineer.

\section{Corresponding Author}

Prof. Andreas Demosthenous

Department of Electronic and Electrical Engineering

University College London

Torrington Place

London WC1E 7JE, UK

Tel: $+44(0) 2076793189$

Fax: +44 (0)20 73889325

Email: a.demosthenous@ucl.ac.uk 